
\title{
CONSIDERATIONS WHEN
USING INFORMAL
EDUCATION CENTERS TO
PROMOTE LEARNING
}

James E. Hollenbeck

Indiana University Southeast • New Albany, Indiana

\section{Introduction}

Robert Oppenheimer, founding director of the San Francisco Exploratorium and the 'father of atomic bomb' advocated for the open-ended nature of informal science education and stated, "...No one ever flunks a museum or a television program or a library or park, while they do flunk a course..." Robert

Oppenheimer (1975, p 10; McComas, 2006, p 29). Experiences from this realm of informal education are devoid of published academic standards or goals and are pursued at the student's individual learning pace. Informal self-directed education proceeds at the learner's pace and desires.

Informal science education is broadly defined as occurring anytime science is experienced outside the science classroom. Sites that support informal science include places like museums, science centers, parks, playgrounds, and county fairs (McComas, 2006). What appears to be a recreational opportunity may hold teachable moments and life changing opportunities for young learners.

Falk and Dierking (2002, p. 11) and McComas (2006 p.28) suggest that informal science learning is superior to classroom-based learning as the child elects to learn. When adults are asked to recall their most memorable moment of science learning, they often recall an anecdotal story from a childhood memory of a trip to a museum, a field trip or the zoo that triggered an interest in that particular subject matter (Abram-Silver, L. 2006; Falk and Dierking, 1997). In a study of 
scientists conducted by the COSMOS Corporation (1998) more than $70 \%$ of 262 people with careers in science reported a memorable informal education activity from their childhood was visiting a planetarium, aquarium, zoo, science or natural history museum, a science-related hobby, science toys, and/or reading science books or magazines for fun.

Falk (2001) suggests that informal learning experiences should be thought of as "free choice learning." These experiences are self-paced, voluntary, and lack a formalized structure for the experience. People are drawn to learn by personal interests and other reasons only understood by them. Learning in this mode allows people to delve deeper into subjects that a classroom environment does not address. "Free choice learning experiences allow the learner the opportunity to stop at will, repeat at will, spend more or less time, and share the learning process with friends and family members " (p.47). Ideally, free-choice learning should support classroom-based science instruction.

\section{Museums as an example of informal learning}

Museums play five important roles in the community. First, museums represent a dedicated space for primary cultural and environmental artifacts. Second, museums provide an opportunity for creative play, interactive exhibits, lectures, and demonstrations (Bell, 1968). Candler (1976) states that museums are not attics of artifacts, but rather functioning institutions that respond to the community and serve as a major provider of educational services. Third, a museum provides a space for learners to experience with self and others how we can use technology to share our understanding of civilizations and environments. Museums are often spaces with rich examples of science, technology, engineering and mathematics (STEM). Fourth, a museum provides an environment for learning that involves the whole person. The learner can experience the exhibit with all their senses. The more interactive the learning is, the more involved the learner can be with the process. Fifth, exhibits that include information in a non-verbal medium are helpful for students with limited auditory skills or limited language proficiency (Ramey-Gassert, 1997). For English language learners and non-verbal learners, museums can provide a mechanism that allows them to participate in a science learning activity without being overwhelmed by language barriers. This permits learners to interact with authentic objects/artifacts without having to learn complex terminology. Being able to acquire new experiences without the encumbrance of learning new 


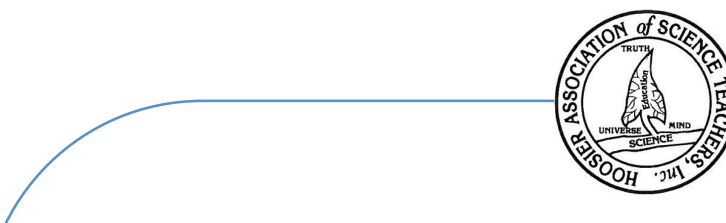

vocabulary words provides the learner a sense of ownership and success from the experience (Abraham-Silver, 2006).

Swann (2014) provides insight into the effects on children who visit museums and those who do not. The analysis was based on data from the Early Childhood Longitudinal Study, Kindergarten cohort (ECLS-K), collected by the Department of Education's National Center for Education Statistics (NCES). The data examined the influence of children's museum visitation in kindergarten with their academic achievement in third grade. The study noted that almost onethird $(30.1 \%)$ of parents indicated that their kindergarten-aged child had visited an art gallery, museum, or historical site within the past month. The study reported that children who visited a museum during kindergarten had higher achievement scores in reading, mathematics, and science rather than children who did not.

\section{Including informal education programming in schools}

Learning experiences should foster and fuel the natural curiosity of a learner. Informal education should afford participants an experience without the risk/fear of failure. Informal environments can spark student interest and prompt them to try new ideas, consider new approaches to problem-solving, and present historical and futuristic ideas and paradigms. NSTA, Board of Directors (2012) recognized the importance of informal science environments on learning. In their position statement they recognize three key points.

First, "the learning experiences delivered by parents, friends, and educators in informal environments can spark student interest in science and provide opportunities to broaden and deepen students' engagement; reinforce scientific concepts and practices" (NSTA, Board of Directors, 2012, p. 1).

Second, "diverse opportunities can help learners understand the relevance of science to their lives, the depth and breadth of science as a field of inquiry" (NSTA, Board of Directors, 2012, p. 1), and how science works in the world. Informal education allows children to be selfdisciplined by exploring in their own way and intentionally directing their own learning (Banks et al. 2007). 
Third, "NSTA underscores the critical role of parents and other caregivers in encouraging and supporting their children's science learning at home, in school, and throughout their community (NSTA, Board of Directors, 2012, p. 2; National Science Teachers Association, 2009).

\section{Recommendations for encouraging the use of informal education centers}

1. Provide a free or reduced fee invitation to teachers, school administrators and group leaders and directors during a daylong open house.

2. A virtual tour of the Center highlighting its core mission, programs, and features. Ideally, this site should be interactive and descriptive.

3. The website should explain what the Center does to promote concepts, processes, or content. If appropriate, align the Center's activity to state or national standards or outcomes.

4. Provide on the Center's website focus questions or an anticipation guide to help people plan their visit. If needed ask K-16 educators if they are interested in developing informal resources for visitors.

5. Have Center staff or volunteers in the community offer programs that uniquely use the materials and resources of the facility to promote interest and awareness. For example, a local museum in Jeffersonville, Indiana, the Vintage Fire Museum offers programs that feature: fire and home safety, the chemistry of building fire, and how technology has changed fire-fighting.

6. Create a virtual tour website, traveling exhibits, or thematic kits that can be shared with clubs, schools, and related organizations.

7. Offer an overnight experience where participants "campout". The Center only serves the participants for an immersive camp experience. Scout groups, 4- $\mathrm{H}$, and other organizations often use the approach in their programs.

8. Partner with schools and universities to offer in-service teachers a chance to obtain renewal credits for their teaching license. 


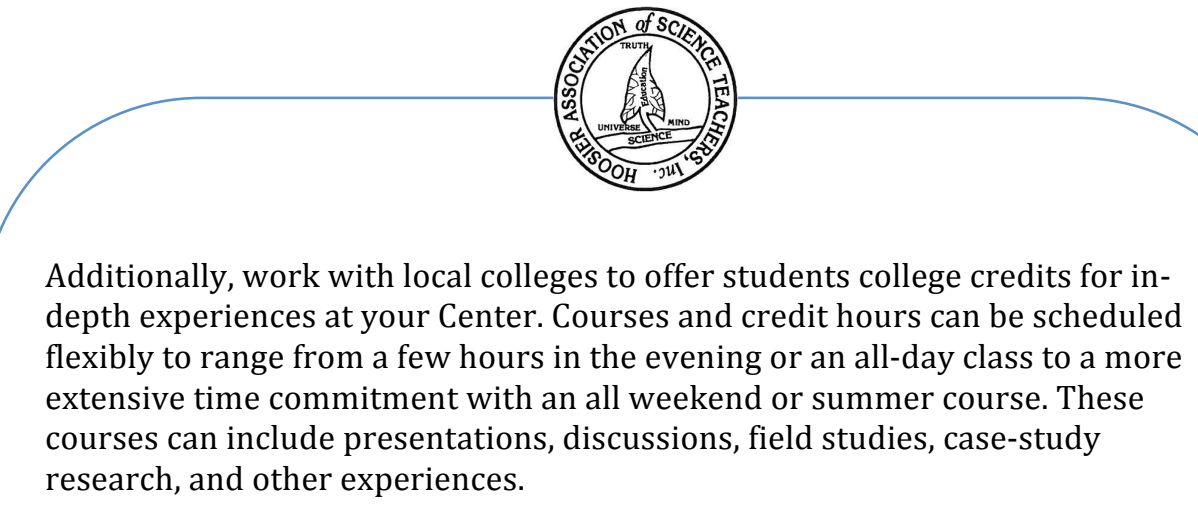

All of these approaches can enhance an informal learning center's visibility in the community, create closer relationships with the community, and provide the community with an invaluable informal educational experience (National Research Council, 2009; National Science Foundation, 1998; National Science Teachers Association, 2009; Summer, 2004).

\section{Final considerations}

First, informal environments for science learning should be developed and implemented with the interests and concerns of all communities, social groups, and cultural groups that the informal setting serves. Approaches should be used that help participants identify with science in personally meaningful ways.

Second, the learning opportunities should be developed in ways that draw upon likely participants' use of everyday language, linguistic practices, and cultural experiences. In designed environments, such as museums, bilingual or multilingual labels should be used to facilitate conversations and sense-making among as many participants as possible (NSTA, 2014).

Finally, spaces should be designed to serve families and groups of people. Professionals familiar with the needs of social and cultural groups should be part of the planning and programming at informal learning centers. 


\section{References}

Abraham-Silver, L. (2006). Commentary: Valuing informal science learning environments. The Science Teacher, 73(1), 12-12.

Banks, J. A., Au, K. H., Ball, A. F., Bell, P., Gordon, E. W., Gutierrez, K., Heath, S. B., Lee, C. D., Lee, Y., Mahiri, J., Nasir, N. S., Valdes, G. \& Zhou, M. (2007).

Learning in and out of school in diverse environments: Life-Long, Life-Wide, Life-Deep. Seattle, WA: UW Center for Multicultural Education \& The LIFE Center.

Bell, M.W. (1968) Children's museums. The American Biology Teacher, 30 (4), 299-301.

Candler, G.M. (1976). Museums in education: The Changing role of education services in British museums. The History Teacher, 9 (2), 183-195. http://dx.doi.org/10.2307/492285

Cosmos Corporation (1998). A report on the evaluation of the National Science Foundation's informal science education program. Washington, DC:

National Science Foundation. Retrieved from http://029c7c0.netsolhost.com/MSPDocs/Evaluation of Informal Science Education Program.pdf

Falk, J. H. (2001). Free choice science education: How we learn science outside of school. New York: Teachers College Press.

Falk, J. H. and Dierking, L.D. (2002). Lessons without limit: How free-choice learning is transforming education. Walnut Creek, CA. Altra Vista Press.

McComas, W. F. (2006) Science teaching beyond the classroom: the role of informal learning environments. The Science Teacher, 27-30.

National Research Council (2009). Learning science in informal environments. Washington, DC: National Academies Press.

National Science Foundation (1998). A report on the evaluation of the National Science Foundation's informal science education program. Retrieved from https://www.nsf.gov/pubs/1998/nsf9865/nsf9865.htm

National Science Teachers Association (2009). NSTA Position Statement: Parent Involvement in Science Learning. Retrieved from http://static.nsta.org/pdfs/positionstatement_parentinvolvement.pdf NSTA Board of Directors (2012). NSTA Position Statement; Learning Science in Informal Environments. Retrieved from www.nsta.org/about/positions/informal.aspx. 
NSTA (2014). NGSS: Learning Opportunities and Demands for Non-Dominant.

Retrieved from http://ngss.nsta.org/appendix-d-all-standards-making-thengss.aspx.

Oppenheimer, R. (1975). The Exploratorium and other ways of teaching physics. Physics Today, 28, 9-13.

Ramsay-Gasert, L. (1997). Science beyond the classroom. The Elementary School Journal, 97 (4), 433-450.

Summers, S. (2004). Museums as resources for science teachers. Science Scope, 27 (9), 28-29.

Swan, D. W. (2014, April). The Effect of Informal Learning Environments on Academic Achievement During Elementary School. Paper presented at the annual meeting of the American Educational Research Association, Philadelphia, PA. Retrieved from Retrieved from http://www.aera.net/Publications/Online-Paper-Repository/AERA-OnlinePaper-Repository/Owner/335159

\section{APA reference for this article:}

Hollenbeck, J. (2018). Considerations when using informal education centers to promote learning. The Hoosier Science Teacher 41(1), 37-43. Doi:

10.14434/thst.v41i123203 